\title{
Avaliação in vivo do efeito hipoglicemiante de extratos obtidos da raiz e folha de bardana Arctium minus (Hill.) Bernh.
}

\author{
Vera Lúcia de Liz Oliveira Cavalli ${ }^{1 *}$, Crissiane Sordi ${ }^{1}$, Karlúcio Tonini ${ }^{1}$, Adriana Grando ${ }^{1}$, \\ Tânia Muneron ${ }^{1}$, Ariene Guigi ${ }^{1}$, Walter Antônio Roman Júnior ${ }^{2}$ \\ ${ }^{1}$ GESPLAN (Grupo de Estudos de Plantas Medicinais) - Universidade Comunitária Regional de Chapecó- \\ UNOCHAPECO, Av. Senador Atílio Fontana 591 E, Caixa Postal 747, \\ 89809-000, Chapecó, SC, Brasil, \\ ${ }^{2}$ Centro de Ciências da Saúde, Laboratório de Farmacognosia, Universidade Comunitária Regional de Chapecó \\ - UNOCHAPECO, Av. Senador Atílio Fontana 591 E, Caixa Postal 747, \\ 89809-000, Chapecó, SC, Brasil
}

\begin{abstract}
RESUMO: O objetivo do presente estudo foi avaliar in vivo o potencial hipoglicemiante, de extratos obtidos da raiz e folha de bardana, Arctium minus (Asteraceae). Também realizaramse ensaios farmacognósticos de controle de qualidade. Nos ensaios biológicos, 60 ratos foram induzidos ao diabetes experimental pela administração de aloxano por via endovenosa, na dose única de $42 \mathrm{mg} / \mathrm{kg}$. No sétimo dia após a indução, dosou-se a glicemia de jejum. Os animais com glicemia superior a $190 \mathrm{mg} / \mathrm{dL}$ foram redistribuídos em quatro grupos para receberem, por 21 dias, algum tipo de tratamento. Grupo 1: Glibenclamida, na dose de 0,071 mg/kg; Grupo 2: extrato bruto liofilizado da raiz de bardana, $500 \mathrm{mg} / \mathrm{kg}$; Grupo 3: extrato bruto liofilizado da folha de bardana, $200 \mathrm{mg} / \mathrm{kg}$; e Grupo 4: soro fisiológico. Após o tratamento, o extrato bruto da raiz de bardana reduziu em $34,6 \pm 5,8 \%$ os níveis glicêmicos, o extrato bruto da folha reduziu $22,9 \pm 6,2 \%$ e a Glibenclamida $34,5 \pm 6,2 \%$. O grupo placebo manteve a glicemia. Este estudo demonstrou que o extrato bruto de Arctium minus, principalmente a raiz, é capaz de diminuir os níveis plasmáticos de glicose, com potência semelhante ao medicamento sintético de referência Glibenclamida.
\end{abstract}

Unitermos: Arctium minus, Asteraceae, bardana, planta medicinal, efeito hipoglicemiante.

\begin{abstract}
In vivo study of the hypoglycemiant efect of extracts from the root and leaf of the bardana Arctium minus (Hill.) Bernh.”. The objective of the present study was to analyze in vivo the hypoglycemiant potential of the extracts from the root and leaf of the medicinal plant bardana, Arctium minus (Asteraceae). It was also carried out through pharmacognostics analysis of quality control. In the biological assays, 60 rats were induced to the experimental diabetes through endovenous injection of alloxan administration, in an only dose of $42 \mathrm{mg} / \mathrm{kg}$. On the seventh day after the induction, the fast glycemia was dosed. The animals with glycemia superior to $190 \mathrm{mg} /$ $\mathrm{dL}$ were redistributed in four groups to receive, for 21 days, some kind of treatment. Group 1: Glibenclamide in the dose of $0.071 \mathrm{mg} / \mathrm{kg}$; Group 2: pure lyophilized extract of bardana root, 500 $\mathrm{mg} / \mathrm{kg}$; Group 3: pure lyophilized extract of bardana leaf, $200 \mathrm{mg} / \mathrm{kg}$; and Group 4: physiological serum. After treatment, the pure extract of bardana root reduced in $34.6 \pm 5.8 \%$ the glycemic levels, the pure extract of the leaf reduced in $22.9 \pm 6.2 \%$ and the Glibenclamide $34.5 \pm 6.2 \%$. The placebo group kept the glicemy. This study suggests that the pure extract of Arctium minus, mainly the root extract, is able to reduce the plasmatic levels of glucose, with similar power to the synthetic medicine of Glibenclamide reference.
\end{abstract}

Keywords: Arctium minus, Asteraceae, bardana, medicinal plant, hypoglicemiant effect.

\section{INTRODUÇ̃̃O}

O Diabetes mellitus é um problema de saúde pública mundial devido ao seu potencial de morbidade e mortalidade. Segundo a Organização Mundial da Saúde (OMS), em todo o planeta, 194 milhões de pessoas têm diabetes, e outros 140 milhões poderão desenvolver a doença nos próximos 20 anos. No Brasil, estima-se que esta doença atinge quase 12 milhões de indivíduos (Diabetes, 2004).
O diabetes geralmente leva a complicações micro-vasculares, predominando a retinopatia, a nefropatia e a neuropatia e complicações macrovasculares, particularmente o acidente vascular cerebral e as doenças da artéria coronária. Juntas, essas doenças fazem do diabetes a sétima causa de óbitos no mundo desenvolvido (Sacks et al., 2002).

Frente a essa realidade, torna-se imprescindível a procura de novas alternativas para o tratamento do diabetes. Atualmente, estudos sobre novas drogas 
hipoglicemiantes vêm sendo realizados, com enfoque especial para as plantas medicinais usadas na medicina popular, pois dados da literatura revelam que é muito mais provável encontrar atividade biológica em plantas orientadas pelo seu uso na medicina popular do que em plantas escolhidas ao acaso (Cechinel-Filho; Yunes, 1998; Barbosa-Filho et al., 2005). Um exemplo é a planta Galega officinalis, que levou ao desenvolvimento da droga hipoglicemiante oral, Metformina (Noel et al., 1997).

A bardana (Arctium minus) é utilizada desde a antiguidade para fins medicinais, destacando-se sua indicação no tratamento do diabetes como agente hipoglicemiante, é também conhecida popularmente como "carrapicho-grande", "pega-pega", entre outras sinonímias; pertence à família Asteraceae e tem origem no Japão. No Brasil, cresce espontaneamente nos campos, sub-bosques e áreas ruderais, sendo considerada muitas vezes uma planta invasora (Corrêa; Batista; Quintas, 1998, Silva, 1989, Lorenzi; Matos, 2002). Entretanto, apesar do uso popular desta planta, poucos estudos têm sido realizados para comprovar a atividade hipoglicemiante da mesma. Sendo assim, neste trabalho efetuaram-se ensaios farmacognósticos de controle de qualidade das raízes e folhas da planta Arctium minus e indução do Diabetes mellitus em ratos pela administração de aloxano para verificação da atividade hipoglicemiante do extrato bruto da raiz e folha de bardana. Na literatura há relatos de uma outra espécie de bardana (Arctium lappa) cultivada no sul do Brasil que mostrou atividade antioxidante (Lima et al., 2006) e inibidora da enzima conversora de angiotensina (Barbosa-Filho et al., 2006).

\section{MATERIAL E MÉTODOS}

\section{Material botânico}

As folhas e as raízes de Arctium minus foram coletadas no mês de setembro de 2003, na cidade de Chapecó, SC, latitude $27^{\circ} 05^{\prime} 33^{\prime \prime}, 85$, longitude $4^{\circ} 35^{\prime} 10^{\prime}, 89$, coordenada $\mathrm{x}-342719,895$ e coordenada $\mathrm{y}-$ 7002259,979 (dados fornecidos por aparelho GPS II plus, GARMIN OLATHE. KS. USA). A exsicata do material vegetal coletado foi identificada por Osmar dos Santos Ribas do Museu Botânico Municipal de Curitiba e foi depositada sob o registro 202442. As folhas frescas foram picadas e secas em temperatura ambiente por quatorze dias. As raízes frescas foram fatiadas e dessecadas em estufa a $40^{\circ} \mathrm{C}$ por sete dias. Após secagem, as folhas e as raízes foram pulverizadas e estocadas.

\section{Ensaios farmacognósticos de controle de qualidade}

Os ensaios efetuados para controle de qualidade foram baseados nos métodos de farmacognosia descritos na Farmacopéia Brasileira, $4^{\mathrm{a}}$ edição: perdas por dessecação, teor extrativo e corte histológico.

\section{Preparação dos extratos brutos}

Para a obtenção dos extratos brutos semelhantes à solução extrativa elaborada pela medicina popular, optou-se tanto para raízes quanto para folhas, pelo método extrativo com água destilada sob refluxo. A proporção utilizada foi de 1:10 droga/solvente $(\mathrm{p} / \mathrm{v})$. Após a extração, as soluções extrativas foram resfriadas, filtradas, liofilizadas e armazenadas a $-20^{\circ} \mathrm{C}$.

\section{Animais}

Foram utilizados 70 ratos (Rattus norvegicus, variedade albinus), machos, adultos jovens de aproximadamente 80 dias, sadios, da linhagem Wistar, pesando entre 250 e 330 gramas, procedentes do Biotério Central da Universidade do Vale do Itajaí (UNIVALI), Itajaí, SC.

O protocolo experimental foi aprovado pelo Comitê de Bioética em Pesquisa da Universidade Regional Integrada URI - Campus Erechim, RS, através do parecer $\mathrm{n}^{\circ}$ 105-1/TCA/04.

Os animais foram acondicionados em gaiolas plásticas coletivas, com dois ou três animais por gaiola, mantidos em fotoperíodo de 12 horas de claro e escuro, ruídos mínimos, temperatura ambiente de aproximadamente $25{ }^{\circ} \mathrm{C}$ e umidade mantida por ar condicionado. Os animais foram alimentados com ração balanceada padrão para roedores (NUVILAB - NUVITAL Nutrientes Prod. Vet. Ltda - Curitiba PR) e água " $a d$ libitum". Antes do início do experimento, os animais passaram por um período de adaptação de sete dias.

\section{Indução do Diabetes mellitus experimental}

Para a obtenção do diabetes experimental, foi seguido o protocolo usado pela Faculdade de Medicina de Botucatu da UNESP (Lerco et al., 2003), com algumas adaptações.

O diabetes experimental foi induzido pela administração de aloxano - Alloxan monohydrate, SIGMA-Aldrich Inc., St. Louis, MO, USA, lote 083K2511- diluído a $2 \%$ em solução de citrato $0,05 \mathrm{M}$, $\mathrm{pH} 4,5$. A droga foi administrada via endovenosa, na dose única de $42 \mathrm{mg} / \mathrm{kg}$ de peso corporal, utilizando-se uma das veias da cauda do animal. Após jejum alimentar de 24 horas, com fornecimento de água "ad libitum", cada rato foi colocado em uma caixa aquecida com lâmpada elétrica (a uma temperatura na faixa de $40{ }^{\circ} \mathrm{C}$ ), durante um período de aproximadamente 10 minutos; para uma melhor visualização das veias da cauda. Após esse procedimento, o animal foi levemente anestesiado por inalação de éter etílico, contido em decúbito ventral, tendo sua cauda exposta, após o que se procedeu à inoculação da droga. A velocidade de infusão do aloxano foi rápida. Decorridos 30 minutos do tratamento, os animais foram alimentados normalmente e receberam uma solução de 
glicose $10 \%$ como única fonte hídrica, durante 24 horas.

\section{Seleção, distribuição e tratamento dos animais}

Da amostra inicial de 70 animais, foram escolhidos aleatoriamente 10 deles para compor o grupo controle (ratos não-diabéticos). Os 60 ratos restantes foram submetidos à injeção endovenosa de aloxano, como descrito anteriormente, e considerados como grupo teste. No sétimo dia após a indução, foi determinada a glicemia de jejum dos dois grupos. Todos os animais do grupo teste que apresentaram glicemia de jejum acima de $190 \mathrm{mg} / \mathrm{dL}$ foram considerados diabéticos. Os demais foram desprezados.

Os animais considerados diabéticos foram redistribuídos em quatro grupos, e diariamente, no mesmo horário, por um período de 21 dias, receberam, através da técnica de gavagem, alguma substância como tratamento. Os animais do grupo 1 (7 animais) receberam o medicamento antidiabético Glibenclamida, na dose de $0,071 \mathrm{mg} / \mathrm{kg}$. Os animais do grupo 2 (8 animais) foram tratados com extrato bruto liofilizado da raiz de Arctium minus, na dose de $500 \mathrm{mg} / \mathrm{kg}$. Enquanto que os do grupo 3 (7 animais) receberam extrato bruto liofilizado da folha de Arctium minus administrado na dose de $200 \mathrm{mg} / \mathrm{kg}$. Já o grupo 4 (6 animais) sem nenhum tratamento (placebo), recebeu apenas soro fisiológico. Todas as substânciasteste foram administradas na proporção de $1 \mathrm{~mL} / 250 \mathrm{~g}$ de peso corporal.

\section{Determinação da glicose sangüínea}

A glicemia foi avaliada no sétimo dia após a indução do diabetes pelo aloxano e no vigésimo segundo dia após início do tratamento com a bardana. Para a realização da coleta de sangue, os animais ficaram em jejum sólido de 12 horas. Após o jejum, cada rato foi colocado em uma caixa aquecida com lâmpada incandescente, a uma temperatura de aproximadamente $40{ }^{\circ} \mathrm{C}$, por um período de 10 minutos e anestesiado em campânula com éter. A seguir, retirou-se, com seringa de insulina, aproximadamente $1,0 \mathrm{~mL}$ de sangue da veia da cauda, sendo o sangue colocado em tubo de ensaio contendo fluoreto de sódio. Em seguida, o sangue foi centrifugado e o plasma foi utilizado para as dosagens plasmáticas de glicose. Para a dosagem glicêmica, empregou-se o método enzimático colorimétrico da glicose-oxidase.

\section{Pesagem dos animais}

Os animais foram pesados semanalmente para adequação da dose durante o tratamento e acompanhamento da evolução clínica.

\section{Tratamento estatístico}

17(1): Jan./Mar. 2007
Método ANOVA, seguido por múltipla comparação (Teste de Duncan). Os resultados foram expressos como média \pm erro padrão da média.

\section{RESULTADOS E DISCUSSÕES}

\section{Ensaios farmacognósticos}

Nos ensaios farmacognósticos de controle de qualidade, obtiveram-se os seguintes resultados: para o teor extrativo da raiz de $2,5 \%$ e da folha $0,99 \%$, perdas por dessecação da raiz de $12 \%$ e folha de $13 \%$. O corte histológico da folha revelou estruturas típicas da espécie Arctium minus, confirmando, assim, a identidade botânica da planta.

\section{Ensaios biológicos}

\section{Animais de experimentação}

Como modelo experimental escolheu-se o rato Wistar, por apresentar inúmeras vantagens em relação a outros animais de maior porte e, principalmente, por apresentarem semelhanças clínicas, laboratoriais e histopatológicas com o diabetes humano (Lerco et al., 2003, Spadella, 1989, Schellini, 1992, Carvalho, 2002).

\section{Método de indução}

Optou-se pela utilização de aloxano como droga diabetogênica, devido às características apresentadas serem semelhantes às encontradas na síndrome diabética em humanos: glicosúria, polifagia, polidipsia, hiperglicemia, entre outras (Carvalho, 2002).

O aloxano é um dos agentes diabetogênicos mais estudado e comumente utilizado no meio científico para a indução de diabetes experimental. Essa droga possui citotoxicidade específica para as células beta do pâncreas, causa insuficiência insulínica primária, provocando uma resposta trifásica nos níveis glicêmicos durante as primeiras horas da administração, seguida do estabelecimento de diabetes permanente nas 24 horas subseqüentes (Lerco et al., 2003). Segundo Zanoello et al. (2002), a citotoxidade seletiva do aloxano é condicionada pela grande capacidade da célula beta em acumular a droga, aliada ao fato de esta célula demonstrar maior sensibilidade aos radicais peróxidos quando comparada a outros tecidos. Utilizou-se o aloxano diluído a $2 \%$ em solução de citrato $0,05 \mathrm{M}, \mathrm{pH} 4,5$, por via endovenosa, pois estudos realizados anteriormente sugerem que outras vias de administração, que não a via endovenosa, atenuam a resposta hiperglicêmica no Diabetes mellitus induzido com aloxano (Soares; Costa; Cecim, 2000, Lerco et al., 2003).

No presente trabalho, dos 60 animais selecionados para receberem a injeção endovenosa de aloxano, três ratos $(5 \%)$ morreram durante procedimentos 
anestésicos e quatro ratos $(6,7 \%)$ morreram durante os primeiros seis dias após a indução. Dos 53 animais restantes, 23 ratos $(38,3 \%)$ não ficaram diabéticos ou apresentaram diabetes de gravidade leve, sendo desprezados, e 30 ratos $(50 \%)$ desenvolveram diabetes dentro dos parâmetros previamente estabelecidos (glicemia superior a $190 \mathrm{mg} / \mathrm{dL}$ ).

Esses resultados foram considerados satisfatórios quando comparados aos relatados por Lerco et al. (2003), que obtiveram 39\% de animais diabéticos, $21,8 \%$ de animais não-diabéticos e um índice de mortalidade de $39 \%$ durante a primeira semana após a indução. O protocolo de indução foi baseado no usado por Lerco et al. (2003), porém com algumas adaptações, como aumento no tempo de jejum antes da injeção de aloxano (de 12 para 24 horas), pois, segundo Lukens, (1948) apud Lerco et al. (2003), o jejum tem um papel importante na resposta de animais à injeção de aloxano. Os autores relatam que, em alguns estudos, 95\% de ratos quando tratados com aloxano administrado com o animal em jejum prolongado de 48 a 60 horas, tornam-se diabéticos, enquanto que, sem o jejum, a administração de uma dose similar de aloxano, diminui essa resposta para $25 \%$. O fornecimento de uma solução de glicose $10 \%$ como única fonte hídrica durante as primeiras 24 horas após a indução é, segundo Mazzanti et al. (2003), fundamental para evitar uma hipoglicemia fatal, devido à liberação maciça de insulina que ocorre após a destruição das células beta. Outra adaptação foi a diluição do aloxano em solução de citrato $0,05 \mathrm{M}, \mathrm{pH} 4,5$, pois a acidez da solução evita a rápida neutralização do aloxano, ainda em solução, o que, segundo Presta e Pereira (1987), poderia prejudicar o seu efeito diabetogênico.
Em relação à grande diferença observada na taxa de mortalidade, Lukens, (1948) apud Lerco et al. (2003), relata que há índices muito variáveis de mortalidade, podendo até mesmo chegar a $100 \%$ na mesma espécie. Isso se deve a múltiplos fatores capazes de mudar os efeitos da droga e a sensibilidade do hospedeiro, envolvendo desde o estado de hidratação da droga, a velocidade de infusão, a via de administração, a dieta, o tempo de jejum, o peso do animal, entre outras.

Baseado nos resultados obtidos pode-se dizer que o jejum prolongado antes da indução, a solução de glicose 10\% nas 24 horas após a indução, o pH ácido da solução e a velocidade de infusão na hora da administração endovenosa, contribuíram significativamente para a obtenção de $50 \%$ de animais diabéticos e um baixíssimo índice de mortalidade.

\section{Evolução clínica}

Os animais do grupo controle (não-diabéticos) evoluíram dentro da normalidade esperada, durante o experimento, apresentando um ganho de peso corporal de $30,6 \pm 3,3 \%$ entre o início e o término deste. A ingestão hídrica, a ingestão alimentar e a diurese mantiveram-se dentro dos níveis esperados para ratos sadios.

Os animais que compuseram o grupo diabético evoluíram com parâmetros clínicos compatíveis com o diabetes, tais como polifagia, polidipsia e poliúria. Os animais dos grupos tratados com extrato bruto da raiz de bardana e Glibenclamida tiveram uma menor ingestão hídrica e menor diurese em relação aos grupos tratados com extrato bruto de folha de bardana e soro fisiológico (grupo placebo).

PESO

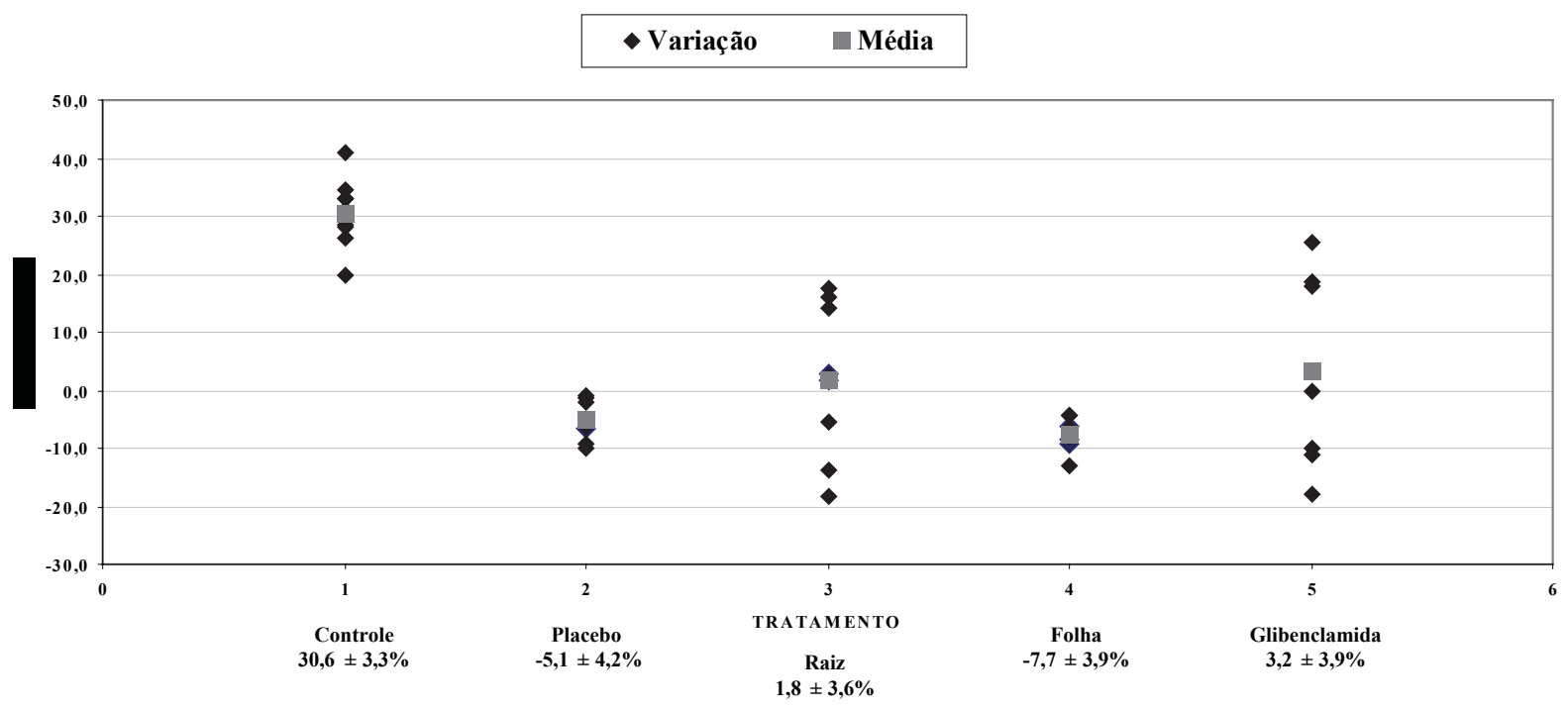

Gráfico 1. Variação de peso dos animais submetidos à avaliação de atividade biológica hipoglicemiante. 
A variação no peso corporal dos animais do grupo controle (não-diabético) e dos grupos diabéticos tratados (raiz, folha, Glibenclamida e placebo), durante a realização do experimento, é demonstrada no Gráfico 1.

O grupo diabético induzido não-tratado (placebo) perdeu 5,1 $\pm 4,2 \%$ de peso corporal; o grupo tratado com o extrato bruto da folha de bardana também perdeu $7,7 \pm 3,9 \%$; o grupo tratado com extrato bruto da raiz de bardana ganhou $1,8 \pm 3,6 \%$ de peso corporal e grupo tratado com Glibenclamida, também ganhou 3,2 \pm $3,9 \%$ de peso.

Constatou-se que a grande variação no erro padrão da média (EPM) relacionado ao peso corporal dos animais diabéticos está intimamente ligados a glicemia, durante o tratamento os animais que mantiveram glicemias superiores a $300 \mathrm{mg} / \mathrm{dL}$ perderam peso enquanto os que mantiveram glicemias inferiores a $300 \mathrm{mg} / \mathrm{dL}$ ganharam peso, essa variação glicêmica, aliada ao número pequeno de animais por grupo do experimento $(\mathrm{n}<10)$, levou a grande variação do EPM. Já os animais sadios (grupo controle) a variação do EPM manteve-se dentro do esperado.

A análise estatística do peso corporal (Teste de Duncan) demonstrou que os grupos raiz, folha, Glibenclamida e placebo não possuem diferenças estatisticamente significantes entre si $(p>0,07)$. Porém, todos são diferentes do grupo controle $(\mathrm{p}<0,05)$.

\section{Evolução laboratorial}

Nas dosagens da glicemia de jejum do grupo controle (não-diabético), realizadas no sétimo e no vigésimo segundo dia do experimento, obtiveramse médias de 113,2 $\pm 3,7 \mathrm{mg} / \mathrm{dL}$ e $100,3 \pm 4,4 \mathrm{mg} / \mathrm{dL}$ respectivamente, valores esses compatíveis com animais normoglicêmicos. Segundo Zanoello et al. (2002) os valores normais da glicemia em ratos variam entre 47,7 a $107 \mathrm{mg} / \mathrm{dL}$.

Os dados relativos à dosagem da glicemia de jejum no sétimo dia após a indução com aloxano e no vigésimo segundo dia após o início do tratamento dos grupos diabéticos tratados com Glibenclamida, raiz, folha e soro fisiológico estão listados na Tabela 1.

Os animais tratados com o extrato bruto da folha de bardana apresentaram no início do tratamento uma média glicêmica de $344,7 \pm 38,9 \mathrm{mg} / \mathrm{dL}$ e após 21 dias de tratamento $274,7 \pm 52,0 \mathrm{mg} / \mathrm{dL}$, demonstrando uma redução de $22,9 \pm 6,2 \%$ nos níveis glicêmicos. $\mathrm{O}$ grupo tratado com o extrato bruto de raiz apresentou uma média glicêmica inicial de $332,5 \pm 45,4 \mathrm{mg} / \mathrm{dL}$ e $229,5 \pm 48,2$ $\mathrm{mg} / \mathrm{dL}$ no final do tratamento, apresentando uma redução de $34,6 \pm 5,8 \%$ nos níveis glicêmicos. Observou-se que tanto o extrato bruto de raiz, quanto o da folha, foram mais eficazes em glicemias menores que $360 \mathrm{mg} / \mathrm{dL}$.

Os animais tratados com Glibenclamida tiveram, no início do tratamento, glicemia média de $381,5 \pm 58,5$ $\mathrm{mg} / \mathrm{dL}$ e no final $248,1 \pm 36,4 \mathrm{mg} / \mathrm{dL}$. A redução média da glicemia foi de $34,5 \pm 6,2 \%$. Observou-se que tanto em glicemias leves, moderadas ou severas, o índice de redução das taxas glicêmicas foi muito próximo, fato esse não observado nos animais tratados com bardana.

Os animais do grupo placebo (tratados com soro fisiológico) apresentaram, no sétimo dia após a indução, valores glicêmicos médios de $356,6 \pm 36,8 \mathrm{mg} / \mathrm{dL}$ e 427,1 $\pm 36,9 \mathrm{mg} / \mathrm{dL}$ no vigésimo segundo dia após o início do tratamento, demonstrando um aumento de $22 \pm 6,7 \%$ nos níveis glicêmicos. Através desses valores, podemos concluir que o aloxano foi capaz de induzir o diabetes e manter o mesmo durante todo o experimento.

A análise estatística dos valores obtidos da glicose sanguínea (Teste de Duncan) demonstrou que os grupos raiz, folha e Glibenclamida não possuem diferenças estatisticamente significantes entre $\mathrm{si}(\mathrm{p}>0,183)$. $O$ grupo raiz ( $p<0,015)$, o grupo placebo $(p<0,001)$ e o grupo Glibenclamida $(\mathrm{p}<0,013)$ são estatisticamente diferentes do grupo controle normal. Já o grupo folha $(\mathrm{p}>0,179)$ não é estatisticamente diferente desse grupo. $\mathrm{O}$ grupo placebo $(\mathrm{p}<0,001)$ é diferente de todos os outros.

Tem sido descrito na literatura que uma droga é considerada eficaz quando reduz os níveis em pelo menos $15 \%$ dos valores iniciais (Martha et al., 2000). Portanto, podemos sugerir que o extrato bruto tanto da folha quanto da raiz de bardana são eficazes na redução dos níveis sangüíneos de glicose em ratos Wistar.

\section{Possíveis mecanismos de ação}

Num estudo realizado em ratos por Grover et al.

Tabela 1. Médias glicêmicas antes do tratamento e após vinte e um dias de tratamento.

\begin{tabular}{|c|c|c|c|}
\hline Grupo & $\begin{array}{l}\text { Glicemia de jejum antes do } \\
\text { tratamento (após a indução } \\
\text { com aloxano) }\end{array}$ & $\begin{array}{l}\text { Glicemia de jejum } \\
\text { após o tratamento }\end{array}$ & $\begin{array}{l}\text { Variação da } \\
\text { glicemia }(\%)\end{array}$ \\
\hline Placebo $(n=6)$ & $356,6 \pm 36,8 \mathrm{mg} / \mathrm{dL}$ & $427,1 \pm 36,9 \mathrm{mg} / \mathrm{dL}$ & (+) $22,0 \pm 6,7 \%$ (a) \\
\hline Folha $(n=7)$ & $344,7 \pm 38,9 \mathrm{mg} / \mathrm{dL}$ & $274,7 \pm 52,0 \mathrm{mg} / \mathrm{dL}$ & (-) $22,9 \pm 6,2 \%$ (b) \\
\hline Raiz $(n=8)$ & $332,5 \pm 45,4 \mathrm{mg} / \mathrm{dL}$ & $229,5 \pm 48,2 \mathrm{mg} / \mathrm{dL}$ & (-) $34,6 \pm 5,8 \%$ (b) \\
\hline Glibenclamida $(n=7)$ & $381,5 \pm 58,5 \mathrm{mg} / \mathrm{dL}$ & $248,1 \pm 36,4 \mathrm{mg} / \mathrm{dL}$ & (-) $34,5 \pm 6,2 \%$ (b) \\
\hline
\end{tabular}

Os valores expressos representam as médias \pm erro padrão da média (EPM); médias na mesma coluna seguidas de letras diferentes diferem significativamente $(\mathrm{p}<0,05)$ entre si. 
(2000), o tratamento com extrato do caroço de Eugenia jambolana demonstrou efeito hipoglicemiante em uma glicemia média (maior que $175 \mathrm{mg} / \mathrm{dL}$ ) e moderada (maior que $250 \mathrm{mg} / \mathrm{dL}$ ). Esses autores ainda citaram que a diminuição da glicose plasmática é dependente dos protocolos de indução de diabetes que variam na intensidade da hiperglicemia. Isso implicaria que o efeito hipoglicemiante dessa planta seja dependente da dose do agente diabetogênico e no grau de destruição das células beta. Além disso, citaram que esse fato seria um indicativo de que parte da atividade hipoglicemiante do E. jambolana, se dê através da liberação de insulina pelas células beta pancreáticas.

Fazendo uma analogia ao trabalho proposto com esses estudos, pode-se perceber que o efeito hipoglicemiante dos extratos brutos, tanto da raiz como da folha da Arctium minus foram mais eficazes em glicemias de $197 \mathrm{mg} / \mathrm{dL}$ a $360 \mathrm{mg} / \mathrm{dL}$ (glicemias leve e moderada), conseguindo-se reduzir a glicemia em 40 a $56 \%$; nas superiores a $360 \mathrm{mg} / \mathrm{dL}$ a redução foi menor que $21 \%$.

Ao término do experimento, quando os animais foram sacrificados e submetidos à autópsia, foi possível visualizar nitidamente uma maior perda de massa muscular dos animais diabéticos não-tratados (grupo placebo), quando comparados aos animais tratados com bardana ou ainda com o medicamento Glibenclamida. $\mathrm{Na}$ falta de insulina, todo o armazenamento de proteínas é inibido, o catabolismo das proteínas aumenta, a síntese protéica cessa e grandes quantidades de aminoácidos são lançados no plasma, sendo usados, na sua maior parte, diretamente para energia ou como substrato para a gliconeogênese (Guyton; Hall, 1997).

Também observou-se um menor crescimento dos animais diabéticos não-tratados em relação aos grupos tratados com Glibenclamida e bardana. Sabese que a insulina exerce efeito muito potente sobre o crescimento. Sua falta em um animal produz retardo do crescimento de mesma intensidade do que ocorre com a falta do hormônio do crescimento da hipófise anterior (Guyton, 1988).

Diante do exposto, pode-se sugerir que pelo menos parte do efeito hipoglicemiante do extrato bruto de Arctium minus, principalmente a raiz, talvez esteja relacionado à insulina, seja pelo aumento da liberação de insulina das células beta que não foram destruídas pelo aloxano, ou ainda, o aumento da sensibilidade das células à insulina.

\section{CONCLUSÃO}

Com base nos resultados obtidos nesse estudo, pode-se concluir que os extratos brutos da raiz e folha de Arctium minus possuem efeito hipoglicemiante em ratos diabéticos induzidos por aloxano, e provavelmente desenvolve efeito semelhante em humanos. Enfim, nossos resultados corroboram com o observado e descrito na medicina popular para essa espécie vegetal.

\section{AGRADECIMENTOS}

Os autores agradecem ao Balcão de Projetos/ FAPE-UNOCHAPECÓ, pelo apoio financeiro. Ao professor João Carlos Palazzo de Mello, da Universidade Estadual de Maringá, pela liofilização dos extratos. Aos professores Luis Flávio de Oliveira e Samara Leite, da UNOCHAPECÓ, pela orientação durante a realização dos exames bioquímicos. As farmacêuticas Andréia Zuffo e Karoline Pain, pelo auxílio técnico.

\section{BIBLIOGRAFIA}

Barbosa-Filho JM, Vasconcelos THC, Alencar AA, Batista LM, Oliveira RAG, Guedes DN, Falcão HS, Moura MD, Diniz MFFM, Modesto-Filho J 2005. Plants and their active constituents from South, Central, and North America with hypoglycemic activity. Rev Bras Farmacogn 15: 392-413.

Barbosa-Filho JM, Martins VKM, Rabelo LA, Moura MD, Silva MS, Cunha EVL, Souza MFV, Almeida RN, Medeiros IA 2006. Natural products inhibitors of the angiotensin converting enzyme (ACE). A review between 19802000. Rev Bras Farmacogn 16: 421-446.

Carvalho P 2002. Análise da cicatrização de lesões cutâneas através da espectrofotometria: estudo experimental em ratos diabéticos. Dissertação (Mestrado em Bioengenharia) Faculdade de Medicina de Ribeirão Preto. Universidade de São Paulo, Ribeirão Preto.

Cechinel-Filho V, Yunes RA 1998. Estratégias para a obtenção de compostos farmacologicamente ativos a partir de plantas medicinais. Conceitos sobre modificação estrutural para otimização da atividade. Quim nova 21: 99-105.

Corrêa AD, Batista RS, Quintas LE 1998. Plantas medicinais: do cultivo a terapêtica. Rio de Janeiro: Vozes.

Diabetes 2004. Disponível em: <www.diabetes.org.br. Acessada em: nov. 2004.

Grover JK, Vats V, Rathi SS 2000. Anti-hyperglicemic effect of Eugenia jambolana and Tinospora cordifolia in experimental diabetes and their key metabolic enzymes involved in carbohydrate metabolism. $J$ Ethnopharmacol 73: 461-470.

Guyton AC 1988. Fisiologia humana. Rio de Janeiro: Guanabara Koogan.

Guyton AC, Hall JE 1997. Tratado de fisiologia médica. Rio de Janeiro: Guanabara Koogan .

Lerco MM, Spadella CD, Machado JLM, Schellini AS, Padovani CR 2003. Caracterização de um modelo experimental de Diabetes Mellitus, induzido pela aloxana em ratos. Estudo clínico e laboratorial. Acta Cir Bras 18: 132142 .

Lima AR, Barbosa VC, Santos Filho PR, Gouvêa CMCP 2006. Avaliação in vitro da atividade antioxidante do extrato hidroalcoólico de folhas de bardana. Rev Bras Farmacogn 16: 531-536.

Lorenzi H, Matos FJA 2002. Plantas medicinais no Brasil nativas ou exóticas. São Paulo: Instituto Plantarum.

Lukens FDW 1948. Alloxan diabetes. Physiol Rev 28: 304-330. 
apud Acta Cir Bras 18: 132-142, 2003.

Martha RCD, Poubel J, Ferreira LCL, Lima RS, Borras MRL, Costa PRC, Roland IA 2000. Atividade hipoglicêmica de Averrhoa carambola L. usada em Manaus como antidiabético. NewsLab 38: 142-148.

Mazzanti CM, Schossler DS, Filappi A, Prestes D, Balz D, Miron V, Morsch A, Schetinger MRC, Morsch VM, Cecim M 2003. Extrato da casca de Syzygium cumini no controle da glicemia e estresse oxidativo de ratos normais diabéticos. Ciência Rural 33: 1061-1065.

Noel PH, Pugh JA, Larme AC, Marsh G 1997. The use of traditional plant medicines for non-insulin-dependent Diabetes mellitus in south Texas. Phytother Res 11: 512-517.

Presta GA, Pereira NA 1987. Atividade do Abagerú (Chrysobalanus icaco L, Chrysobalanaceae) em modelos experimentais para o estudo de plantas hipoglicemiantes. Rev Bras Farm 68: 91-101.

Sacks DB, Bruns DE, Goldstein DE, Maclaren NK, McDonald JM, Parrott M 2002. Guidelines and recommendations for laboratory analysis in the diagnosis and management of Diabetes mellitus. Clin Chem 48: 436-472.

Schellini AS 1992. Retinopatia diabética experimental: estudo estrutural, ultraestrutural e morfométrico da retina de ratos normais, diabéticos e diabéticos tratados. (Tese de Doutorado). Universidade Estadual Paulista - Faculdade de Medicina de Botucatu.

Silva AA 1989. Plantas medicinais. Itajaí-SC: EPAGRI, CDROM.

Soares JCM, Costa ST, Cecim M 2000. Níveis glicêmicos e de colesterol em ratos com Diabetes mellitus aloxano induzido tratados com infusão de Bauhinia candicans ou Syzygium jambolanum. Ciência Rural 30: 113118.

Spadella CT 1989. Avaliação funcional do transplante pancreato-duodenal no rato diabético: estudo clínico laboratorial, anátomo-patológicoeimunohistoquímico (Tese de Doutorado). Universidade Estadual Paulista, Faculdade de Medicina de Botucatu.

Zanoello AM, Melazzo-Mazzanti C, Kerpel-Gindri J, Filappi Andreane, Prestes D, Cecim M 2002. Efeito protetor do Syzygium cumini contra Diabetes mellitus induzido por aloxano em ratos. Acta Farm Bonaerense 21: 3136 